\title{
UM ESTUDO DO ÍNDICE PAULISTA DE VULNERABILIDADE SOCIAL SOB A ÓTICA DE MÉTODOS DE APOIO À DECISÃO MULTICRITÉRIO
}

\author{
Fernanda C. Soares*, Leonardo T. Duarte.
}

\section{Resumo}

O Índice Paulista de Vulnerabilidade Social (IPVS) é responsável pela classificação dos setores censitários (microrregiões) do estado de São Paulo em 7 diferentes grupos, de acordo com o grau de vulnerabilidade encontrado. Atualmente, este índice é obtido através do uso da Análise Fatorial, o que lhe confere certo caráter relativo. O presente estudo visa analisar o IPVS sob a ótica de um método de apoio à decisão multicritério. Mais precisamente, consideramos o método Promethee, o qual junto com o PCA, permite uma melhor visualização dos dados, uma vez que é possível representá-los em sub-espaços de dimensões reduzidas, como em um gráfico 2D, por exemplo.

\section{Palavras-chave:}

IPVS, Apoio à Decisão Multicritério, Pesquisa Operacional.

\section{Introdução}

Em 2002, a Fundação Seade criou o Índice Paulista de Vulnerabilidade Social (IPVS), cujo objetivo é o de oferecer um panorama mais detalhado da vulnerabilidade. Atualmente, são analisados nove critérios, como renda domiciliar per capita e idade média dos responsáveis. Após a obtenção dos dados, é feita uma Análise Fatorial (AF), sendo possível classificar os setores em sete diferentes grupos.

O objetivo do projeto é o de analisar o IPVS através do Promethee, que é um método MCDA (Multiple-Criteria Decision Analysis). Ademais, objetiva-se desenvolver uma análise mais visual do problema através da projeção em um gráfico 2D. Para tais análises foram utilizados dados reais do município de Limeira, SP e feita a implementação em software Matlab.

\section{Resultados e Discussão}

Atualmente, com o uso da AF, a classificação dos setores é realizada através da definição de limiares para os scores, os quais são definidos de acordo com os dados analisados, ou seja, os parâmetros para classificação mudam de acordo com os dados.

Com a implementação do método Promethee, em conjunto com a análise principal de componentes (PCA), foi possível traçar os critérios e setores censitários em um plano, assim como a Figura 1 apresenta. Embora os dados estejam num espaço de dimensão 9 , os mesmos são bem representados $(99,98 \%)$ em duas dimensões.

Os vetores com mesma direção representam critérios diretamente relacionados, aqueles com sentidos opostos possuem relação inversa. Quanto mais se aproximam de $90^{\circ}$, mais descorrelacionados entre si são os critérios.

Por outro lado, as cores representam os grupos de vulnerabilidade existentes. Vemos, portanto, que aqueles que são classificados, atualmente, como pertencentes ao mesmo grupo nem sempre apresentam desempenho parecido nos critérios analisados, o que acaba sendo mais evidente no grupo amarelo, que representa os setores censitários com alta vulnerabilidade. Ou seja, embora recebam a mesma classificação, os setores possuem características diferentes, e portanto, devem receber medidas diferentes. A análise visual permite apresentar de maneira mais didática tais comparações.

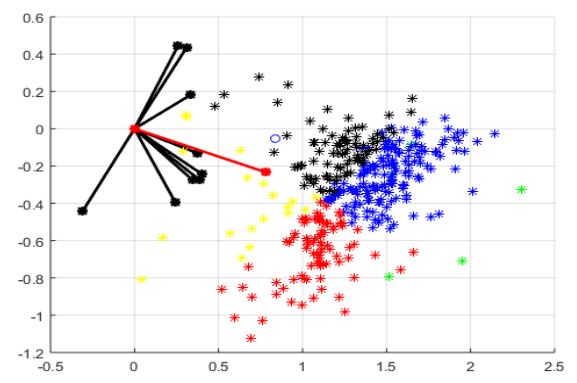

Figura 1. Representação dos critérios e alternativas

\section{Conclusões}

Conclui-se que o atual método utilizado para cálculo e classificação do IPVS poderia ser substituído por um método com menor caráter relativo, possibilitando comparação entre diferentes anos e cidades, dado que os parâmetros seriam os mesmos. O Promethee em conjunto com o PCA oferece tal oportunidade, embora, por ser um método de tomada de decisão, também apresente subjetividade, porém, em menor escala. Ademais, é possível de forma mais rápida e simples a comparação entre os critérios, e análise para melhoria nos critérios específicos de cada setor.

\section{Agradecimentos}

Agradecemos ao PIBIC/CNPq pelo apoio a este projeto e também ao Prof. Dr. Álvaro de Oliveira D'Antona, Prof. Dr Eduardo Marandola Jr e ao mestrando Hugo Trevizan Paggiaro pelo fornecimento dos dados.

Mareschal, Bertrand, and Jean-Pierre Brans. "Geometrical representations for MCDA." European Journal of Operational Research 34.1 (1988): 69-77.

Rencher, Alvin C. Methods of multivariate analysis. Vol. 492. John Wiley \& Sons, 2003.

Metodologia do IPVS. Disponível em:

<http://indices- ilp.al.sp.gov.br/view/pdf/ipvs/metodologia.pdf> XXV Congresso de Iniciação Científica da UNICAMP 